13. Global Initiative for Asthma. Global Strategy for Asthma Management and Prevention [Internet] // https:// ginasthma.org/wp-content/uploads/2019/01/2018-GINA.pdf.

14. Постникова Л.Б., Гудим А.Л., Болдина М.В., Коротаева Л.А., Абанин А.М. Клинические проявления, аспекты диагностики и лечения саркоидоза легких в условиях Нижнего Новгорода // Вестник современной клинической медицины. Оригинальные исследования. 2016. Т. 9, вып. 4. С. 44-51.

15. Внебольничные инфекции дыхательных путей. Руководство для врачей / под ред. А.И. Синопальникова, Р.С. Козлова. М.: Изд-во «Премьер МТ», 2007. C. $295-333$.

16. Johansson N., Kalin M., Tiveljung-Lindell A., et al. Etiology of community-acquired pneumonia: increased microbiological yield with new diagnostic methods // Clinical Infectious Diseases. 2010. Vol. 50. P. 202-209.

17. Ежлова Е.Б., Демина Ю.В., Шеенков Н.В. и др. Лабораторная диагностика внебольничных пневмоний. Методические указания МУК 4.2.3115-13. Федеральная служба по надзору в сфере защиты прав потребителей и благополучия человека. М., 2013. 48 c.

18. Müller B., Harbarth S., Stolz D., et al. Diagnostic and prognostic accuracy of clinical and laboratory pa- rameters in community-acquired pneumonia // BMC Infectious Diseases. 2007. Vol. 7. P. 10.

19. Тюрин И.Е. Методы визуализации // Респираторная медицина. 2 изд., перераб. и доп. Т. 1 / под ред. А.Г. Чучалина. М.: Изд-во «ГЭОТАР-Медиа», 2017. C. $245-302$.

20. Чучалин А.Г., Синопальников А.И., Козлов Р.С. и др. Клинические рекомендации по диагностике, лечению и профилактике тяжелой внебольничной пневмонии у взрослых // Пульмонология. 2014. № 14 (4). C. 13-48.

21. Boyles T.H., Brink A., Calligaro G.L., et al. South African guideline for the management of community acquired pneumonia in adults // Journal of Thoracic Disease. 2017. Vol. 9 (6). P. 1469-1502.

22. Rodriguez A., Lisboa T., Blot S., et al. Mortality ICU patients with bacterial community acquired pneumonia: when antibiotics are not enough // Intensive Care Medicine. 2009. Vol. 35. P. 430-438.

23. Козлов Р.С., Авдеев С.Н., Брико Н.И. и др. Вакцинопрофилактика пневмококковых инфекций у взрослых. Резолюция совета экспертов (Москва, 16 декабря 2017 г.) // Клиническая микробиология и антимикробная химиотерапия. 2018. Т. 20 (№ 1). С. 5-8.

\title{
AN ANALYSIS OF HOW SENIOR STUDENTS OF THE MEDICAL INSTITUTE KNOW BASIC CONCEPTS OF BRONCHOPULMONARY SYSTEM DISEASES
}

(C) 2020

\author{
Dyachkova Anna Albertovna, candidate of medical sciences, \\ associate professor of Therapy with Courses of Physical Therapy Department \\ Khoreva Darya Viktorovna, student of Medical Institute \\ Blinkova Marina Sergeevna, student of Medical Institute \\ National Research Ogarev Mordovia State University (Saransk, Russian Federation)
}

Abstract. Respiratory diseases are one of the most pressing problems of modern internal medicine, which is associated with their prevalence, significant impact on the quality of life and social activities of a person. This study is done not only by the complexity of diagnosis and treatment of major respiratory diseases, but also by the rapid development of modern pulmonology. The paper determines the level of knowledge of COPD and community-acquired pneumonia basic concepts among students of 5-6 courses at the Medical Institute of National Research Ogarev Mordovia State University majoring in «General medicine» with the use of an anonymous questionnaire. The survey was conducted using unique questionnaires developed by the authors on the basis of clinical national recommendations for chronic obstructive pulmonary disease and community-acquired pneumonia. The study found that less than half of senior students do not give correct answers to basic questions about the etiology, pathogenesis, clinical picture or treatment of chronic obstructive pulmonary disease (COPD). More than half of 5-year-students have difficulties answering questions about the etiology, classification, diagnosis, and treatment of community-acquired pneumonia. The results of the survey predispose to additional educational solutions in the field of chronic obstructive pulmonary disease, community-acquired pneumonia and to focus more on prevention and therapy.

Keywords: chronic obstructive pulmonary disease; community-acquired pneumonia; Medical Institute; clinical national guidelines; pulmonology; educational solutions; actual problem; bronchopulmonary system.

\section{ЕДИНСТВО ФИЗИЧЕСКОГО И НРАВСТВЕННОГО ВОСПИТАНИЯ: ЦЕННОСТНЫЕ ОСНОВАНИЯ}

(C) 2020

Клычков Сергей Александрович, преподаватель кафедры физической и тактико-специальной подготовки Самарский юридический институт ФСИН России (2. Самара, Российская Федерачия)

Аннотащия. В статье обосновывается актуальность проблемы воспитания человека, тело и дух которого находятся в гармоничном единстве - человека здорового и физически, и нравственно. В качестве одного из путей решения данной проблемы предлагается формирование нравственной личности в рамках физического 
воспитания. Приводятся доказательства взаимосвязи физического и нравственного развития человека в процессе воспитания. Обосновывается положение о том, что воспитание есть приобщение к ценностям, и доказывается, что воспитание человека в гармонии тела и духа возможно в процессе его приобщения к ценностям физической культуры и к нравственным ценностям. Раскрывается специфика ценности как осознанного смысла, определяющего отношение человека к миру, к людям и к себе самому, и показывается место отношений в нравственной культуре и в физической культуре человека. Доказывается, что ценности могут быть как компонентами физической культуры, воплощая идеалы и представления об эталоне физически совершенного человека, так и компонентами нравственной культуры (эталон человека нравственного). Определяется соотношение нравственных ценностей и ценностей физической культуры и выявляются конкретные ценности, являющиеся ценностными основаниями единства физического и нравственного воспитания: «свобода», «справедливость», «достоинство», «культура», «нравственное совершенство», «милосердие», «интеллигентность». Раскрывается суть нравственной составляющей физического воспитания, заключающейся в том, что в процессе такого воспитания формируется не только отношение личности к здоровью, к здоровому образу жизни, к себе и к другим людям, но и нравственность человека.

Ключевые слова: воспитание; физическое воспитание; нравственное воспитание; ценность; ценностные основания; единство; нравственность; культура; физическая культура; нравственная культура; нравственные ценности; ценности физической культуры; отношения.

Формирование личности современного молодого человека осуществляется под влиянием множества факторов, среди которых и массовая культура, пропагандирующая успех любой ценой, красивую жизнь, предлагающая образцы поведения, искажающие представления о добре, справедливости, милосердии, великодушии, патриотизме, свободе и ответственности.

Сегодня модно быть красивым и стройным. Средства массовой информации, социальные сети формируют стереотип, что жизненные достижения зависят не столько от личностных качеств человека, сколько от его внешности, от того, как он выглядит. Внешняя картинка полностью заслоняет внутренний мир, в том числе и сферу нравственности. Многие молодые люди стремятся к физическому совершенству, но делают это только для себя. Они не задумываются о том, что, например, физическая сила, развитая в процессе систематических занятий в спортзале, может быть направлена на помощь другим людям. Человек, не обладающий нравственными принципами, но стремящийся к высоким достижениям в спорте, легко преступает нравственные нормы ради спортивного успеха. О этом свидетельствуют и многочисленные допинговые скандалы. Тем самым нарушается гармония тела и духа человека.

Обретение такой гармонии возможно в процессе формирования нравственной личности в рамках физического воспитания, которое связано, в том числе, и со становлением «нравственной культуры личности, проявляющейся, главным образом, в совокупности норм, правил и обычаев, которые сложились в социуме в отношении повседневной физкультурно-спортивной и трудовой практики и отражают трудолюбие, честность, правдивость, целеустремленность, инициативность, волю, активность, дисциплинированность, коллективизм, доброту, порядочность» [1, с. 67].

Тем самым высвечивается педагогическая проблема воспитания человека здорового и физически, и нравственно. Если физическое здоровье понимается как отсутствие хронических заболеваний, как сила, ловкость, выносливость и другие качества, характеризующие телесность человека, то нравственное здоровье для нас - это присущие личности нравственные качества (честность, милосердие, доброта и др.), по которым можно судить о его духовности.

Физическое и нравственное развитие человека рассматривается многими учеными как процессы взаимосвязанные. Так, Л.П. Матвеев утверждает, что результаты развития физической силы, физических качеств и двигательных способностей людей не принесут пользы обществу, если физически развитый человек «не воспитан нравственно, если у него не выработаны твердые моральные принципы и нет активного стремления приложить свои силы на благо общества. Иначе говоря, общественно полезный эффект физического воспитания определяется кроме прочего тем, насколько тесно соединены физическое и нравственное воспитание» [2, с. 21].

«Подлинная человечность, - подчеркивает Р. Шустерман, - не просто задается генетикой, но достигается воспитанием, в котором тело, дух и культура должны быть объединены самым тесным образом» [3, c. 53].

Понятие «воспитание» имеет большое количество трактовок в научной литературе. Так, В.М. Полонский, рассматривая воспитание в узком смысле, отмечает, что это «целенаправленная деятельность по формированию у человека нравственно-волевых взглядов, качеств, убеждений, нравственных представлений, определенных привычек и правил поведения» [4, с. 156]. Взгляды, качества, убеждения, правила поведения так или иначе связаны с системой ценностей, присущих человеку. В данном контексте нам более близка точка зрения А.В. Бездухова и Ю.В. Лопуховой, обосновывающих точку зрения, согласно которой воспитание понимается как приобщение человека к ценностям [5, с. 69]. Основываясь на данном положении ученых, мы утверждаем, что воспитание человека в гармонии его тела и духа возможно в процессе его приобщения к ценностям, которые, как утверждает П.С. Гуревич, есть «личностно окрашенное отношение к миру, возникающее на основе не только знания и информации, но и собственного жизненного опыта людей» [6, с. 43].

Ценность, по мнению В.Н. Сагатовского, позволяя найти ответ на вопрос: «Во имя чего?», определяет выбор личностью целей и средств собственной деятельности [7, с. 32].

Как утверждает М. Хайдеггер, ценность «есть опредмеченная цель, определенная потребностями такого представления, которое самоутверждается в мире как картине» [8, с. 56].

С точки зрения В.А. Блюмкина, ценность представляет собой значимость конкретной вещи для человека и общественное отношение. Иными словами, свойства и отношения [9, с. 5]. 
Ценности есть идеальные представления, смыслы моральных понятий, утверждает В.А. Титов [10, с. 13].

Б.С. Братусь утверждает, что ценности, как сущее, представляют собой «осознанные общие смысловые образования» $[11$, с. 27]. Именно смыслы определяют относительно постоянные отношения человека к себе, к другим людям, к обществу в целом. Понимание Б.С. Братусем ценности как осознанного смысла, на основании которого определяется отношение субъекта к окружающей действительности, включая других людей, и к себе, согласуется с пониманием ценности М.С. Каганом, рассматривающим ценность как отношение к... Отметим, что ученый ведет речь о специфическом отношении, связывающем «объект не с другим объектом, а с субъектом как носителем личностных и культурных качеств» [12, с. 67].

Отношения находят отражение как в нравственной культуре, так и в физической культуре человека.

Нравственная культура личности, по утверждению Т.В. Мишаткиной, проявляется в определенном уровне морального сознания, в «специфике нравственных отношений с окружающими; особенностях поведения и общения» [13, с. 143]. Ценности человека, проявляя себя в его образе мыслей и действий, в отношениях к другим людям, составляют ядро нравственной культуры личности.

Физическая культура человека связана с физкультурно-оздоровительной деятельностью как типом его отношения к здоровью и здоровому образу жизни. Физическая культура является компонентом общей культуры личности и обладает ценностным потенциалом. Речь здесь идет, прежде всего, о ценностях «здоровье» и «здоровый образ жизни» как о нравственных ценностях. Однако данные ценности, как мы полагаем, в полной мере не охватывают нравственный аспект жизни человека.

В то же время, по утверждению В.Н. Сагатовского, образ жизни непосредственно проявляется в деятельности человека, выбираемой «на основе базовых ценностей в определенных объективных условиях и в определенном отношении к состоянию духа» [7, с. 41]. Иными словами, здоровый образ жизни также может основываться на конкретных ценностях. Тем самым мы находим подтверждение нашему предположению о том, что ценностные основания физической культуры не ограничиваются ценностями «здоровье» и «здоровый образ жизни».

Сама категория «физическая культура» обладает значением ценности. Доказательство данного тезиса осуществлено С.А. Жмуровым, который утверждает, что «физическая культура является особой отраслью культуры, в рамках которой человек опредмечивает и распредмечивает ее ценности, являющиеся, с точки зрения ученого, результативной ее стороной и используемые для физического совершенствования людей» $[14$, с. 135]. Здесь речь ведется в первую очередь о ценностях физической культуры. Однако, с нашей точки зрения, утверждение об использовании ценностей только в рамках физического совершенствования человека существенно сужает возможности данного феномена в воспитании личности в целом. Ценности, выражая сущность культуры, образуя ее внутренний стержень, определяют отношения человека к окружающей действительности, к людям и к самому себе.
Значением ценности обладает и нравственная культура. Так, Г.П. Васянович полагает, что нравственная культура есть духовная ценность [15]; И.М. Шадрина выделяет в структуре нравственной культуры ценностный компонент [16]. Несмотря на то, что и Г.П. Васянович, и И.М. Шадрина говорят о нравственной культуре учителя, мы считаем, положения ученых могут быть экстраполированы на понимание нравственной культуры личности в целом.

Н.Б. Крылова рассматривает ценность как регулятивный компонент культуры, в котором воплощается представление об эталоне (идеале). Ученый также подчеркивает связь ценности с нормой и значением, утверждая, что ценности выражаются через нормы и значения [17]. Тем самым можно утверждать, что ценности могут быть как компонентами физической культуры, воплощая идеалы и представления об эталоне физически совершенного человека, так и компонентами нравственной культуры (эталон человека нравственного).

Ценностный потенциал категория «физическая культура» подчеркивается и другими учеными. Так, С.С. Коровин и В.Ф. Усманов, предлагая определение понятию «физическое воспитание», пишут: «Физическое воспитание представляет собой специализированный педагогический процесс направленного использования ценностей физической культуры для преимущественного становления системы двигательных способностей человека» $[18$, с. 7]. Однако исследователи ограничивают возможности ценностей развитием двигательной активности человека.

Шире ценностный потенциал физической культуры, а тем самым и физического воспитания, понимается Л.И. Лубышевой, которая говорит не о физическом воспитании, а о физкультурном воспитании, считая данную формулировку более корректной. Как считает Л.И. Лубышева, понятия «физическое развитие», «физическое воспитание» и «физкультурное воспитание» не тождественны. Так, физическое развитие есть совершаемый в организме человека объективный процесс; физическое воспитание - активное воздействие человека на данный процесс; физкультурное воспитание - процесс целенаправленного приобщения личности к ценностям физической культуры.

Физическое воспитание Л.И. Лубышева рассматривает как часть физкультурного воспитания, ориентирующего педагогическую систему на формирование физической культуры личности. Ученый утверждает, что физкультурное воспитание непосредственно связано с целенаправленным познанием и непротиворечивой реализацией в физкультурной практике предпосылок гармоничного совершенствования физического потенциала человека, созданных природой, а само физкультурное воспитание есть «педагогический процесс целенаправленного, регулируемого изменения физических и духовных кондиций человека» [19].

$\mathrm{B}$ дальнейшем развивая идею физкультурного воспитания, Л.И. Лубышева подчеркивает взаимосвязь воспитания человека и культуры (воспитание посредством культуры) и утверждает, что физкультурное воспитание возможно через освоение личностью ценностного потенциала физической культуры [20]. Аналогичным образом, нравственное воспитание 
предполагает приобщение личности к ценностям, являющимся компонентом нравственной культуры.

Важным компонентом физического воспитания является формирование ценностного отношения к физической культуре и по мнению А.С. Запесоцкого $[21$, с. 130]. И продолжим - к нравственности, если говорить о нравственном воспитании.

Таким образом, можно утверждать, что единство физического и нравственного воспитания имеет ценностные основания. Для того чтобы подтвердить данное утверждение, обратимся к определению категории «физическое воспитание», данному В.И. Андреевым. По утверждению В.И. Андреева, физическое воспитание представляет собой «процесс, являющийся составной частью общего воспитания личности, направленный на развитие, саморазвитие физической культуры человека» [22, с. 368]. Тем самым физическое воспитание как часть воспитания в общем его понимании несет в себе характеристики последнего. А как уже было отмечено выше, воспитание есть приобщение к ценностям. Аналогичным образом и нравственное воспитание.

Связь воспитания с тем, что наиболее важно для личности школьника, то есть с тем, что значимо, ценно для него, прослеживается и в трактовке понятия «воспитание» С.В. Кульневичем, который подчеркивает, что «воспитание может быть рассмотрено и как совместная с учеником деятельность учителя, направленная на развитие способностей придавать и порождать смысл. Благодаря такой переориентации понимания воспитания появляется возможность обращаться к тому, что представляет наибольшую ценность для ученика» [23, с. 70].

Ценностный аспект воспитания подчеркивается и М.С. Каганом, который пишет, что воспитание есть «формирование системы ценностей, с ее специфическим содержанием. <..> Воспитание есть способ превращения ценностей социума в ценности личности» [12, с. 176].

М.С. Каган, а за ним А.В. Бездухов и Ю.В. Лопухова, о которых речь шла выше, полагают, что сущность воспитания состоит в приобщении ребенка к ценностям. Основываясь на данном положении ученых, отметим, что сущность физического воспитания может быть представлена как приобщение личности к ценностям физической культуры.

А.Г. Асмолов, рассматривая психологический объект воспитания, понимает под данным объектом смысловую сферу личности, систему личностных смыслов и «реализующих их в деятельности смысловых установок» [24, с. 314]. Иными словами, систему ценностей.

Итак, мы обосновали положение о том, что единство физического и нравственного воспитания имеет ценностные основания. Встает вопрос: «К каким конкретным ценностям необходимо приобщать личность?»

Мы ведем речь о гармонии тела и духа человека, иными словами, о его нравственном и физическом воспитании в их единстве. В свете вышесказанного, осуществляя такое воспитание, необходимо приобщать человека к нравственным ценностям и к ценностям физической культуры. Для того, чтобы отобрать конкретные ценности, к которым надо приобщать личность, нужно определить соотношение нравственных ценностей и ценностей физической культуры.
Обращение к научной литературе показывает, что проблема ценностей физической культуры, как, впрочем, и нравственных ценностей, уже стала предметом научного интереса многих ученых.

Например, М.Я. Виленским среди ценностей физической культуры и спорта выделяются ценности 1) физические (здоровье, телосложение и др.), 2) социально-психологические (трудолюбие, навыки общения и др.), 3) психические (эмоциональные переживания, творческие задатки и др.), 4) культурные (познание, самоутверждение и др.). Помимо указанных ученый относит к ценностям физической культуры и спорта материально-технические условия и престиж занятий спортом в целом [25].

С.А. Жмуров утверждает, что классификация ценностей физической культуры может быть осуществлена в соответствии с конкретным видом отношений, в рамках которого осушествляется реализация ценностей: «отношение к культуре (культура, интеллигентность, красота), отношение к знаниям (знание), отношение к человеку как к Другому (справедливость, милосердие, эмпатия), отношение к своему телесному Я (телесность, здоровье, здоровый образ жизни, физическое совершенство, сила, ловкость), отношение к своему душевному Я (нравственное совершенство, интерес), отношение к своему духовному Я (свобода, самостоятельность, самоопределение, самореализация)» [26, с. 25].

А.Я. Борисов рассматривает ценности физической культуры в контексте блага и пользы. По его мнению, «ценностями физической культуры в контексте блага являются: жизнь человека, здоровье, знание, культура, нравственное совершенство, свобода, справедливость, тело человека, физическое совершенство. Ценностями физической культуры в контексте пользы являются: двигательная активность человека, здоровый образ жизни, настойчивость в достижении цели, престиж занятий физической культурой и спортом, самоопределение, самоорганизация, самореализация, творчество, трудолюбие» [27, с. 88].

Обращение к работам, посвященным проблеме нравственных ценностей, показывает, что перечень таких ценностей весьма обширен. Обратимся к критериям, по которым выделяются нравственные ценности. Здесь мы опираемся на работу И.В. Москаленко [28].

В качестве критериев выделения нравственных ценностей И.В. Москаленко называет следующие: 1) различение категории доброе/злое; 2) направленность на других людей, проявляемая в нравственных отношениях; 3) сопряжение чувств и действий человека с чувствами и действиями другого человека, осуществляемое на добровольной основе; 4) осознание человеком соответствия или несоответствия своего поведения нравственности, осуществляемое с опорой на стыд и совесть [28, с. 64-65].

В соответствии с данными критериями И.Б. Акимовым были выделены следующие конкретные нравственные ценности: «По основанию "направленность ценностей на другого человека" - ценности "справедливость", "милосердие", "честность" [29, с. 9]. По основанию "добровольное самодеятельное согласование чувств, стремлений и действий конкретной личности с чувствами, стремлениями и действиями другого человека и общества в целом" - ценности 
"свобода", "ответственность". По основанию "внутренние регуляторы стыда, совести и вины как субъективное сознание соответствия или несоответствия собственного поведения нравственным ценностям" ценности "совесть", "долг"» [29, с. 9]. Кроме того, И.Б. Акимов предлагает в качестве основания выделения нравственных ценностей «одобрение и оценивание поступков человека», в соответствии с которым выделяет ценности «честь» и «достоинство» [29, с. 9].

Сравнительный анализ нравственных ценностей и ценностей физической культуры, предложенных вышеназванными авторами, показывает, что, во-первых, существуют определенные точки соприкосновения данных ценностей. Так, ценности «свобода», «справедливость», «достоинство» трактуются учеными и как нравственные ценности, и как ценности физической культуры. Во-вторых, среди ценностей физической культуры присутствуют те, которые, хотя и не называются И.Б. Акимовым, априори могут быть отнесены к нравственным ценностям: «культура», «нравственное совершенство», «милосердие», «интеллигентность». Тем самым можно говорить о конкретных ценностях, являющихся ценностными основаниями единства физического и нравственного воспитания. Это «свобода», «справедливость», «достоинство», «культура», «нравственное совершенство», «милосердие», «интеллигентность».

Выявленные ценностные основания единства физического и нравственного воспитания позволяют определить суть нравственной составляющей физического воспитания, заключающейся в том, что в процессе такого воспитания формируются не только отношение личности к здоровью, к здоровому образу жизни, к себе и к другим людям, но и нравственность человека. В процессе физического воспитания возникают эффекты со-чувствия, со-действия, со-помощи, со-участия, влияющие на становление у человека стоящих за физическим развитием нравственных ценностей, мир которых есть мир его нравственности. Нравственные ценности в сочетании с ценностями физической культуры обеспечивают взаимосвязь физического и духовного в человеке, гармонию телесности и нравственности.

\section{Список литературы:}

1. Коровин С.С. Теория и методика формирования физической культуры личности: учебно-методическое пособие. Оренбург: ОГПУ, 2005. 72 с.

2. Матвеев Л.П. Теория и методика физической культуры. М.: Физкультура и спорт, 1991. 543 с.

3. Шустерман Р. Мыслить через тело: гуманитарное образование // Вопросы философии. 2006. № 6. C. 52-67.

4. Полонский В.М. Большой тематический словарь по образованию и педагогике. М.: Народное образование, $2017.840 \mathrm{c}$.

5. Бездухов А.В., Лопухова Ю.В. Воспитание как движение, превращающее возможное в действительное // Известия РАО. 2011. № 1 (17). С. 66-75.

6. Гуревич П.С. Преображение ценностей как чрезвычайная ситуация. М.: МПСИ, 2007. 120 с.

7. Сагатовский В.Н. Философия развивающейся гармонии (философские основы мировоззрения): в 3 ч. Ч. 3. Антропология. СПб.: Петрополис, 1999. 288 с.

8. Хайдеггер М. Время и бытие. М.: Наука, 2007. $624 \mathrm{c}$.
9. Блюмкин В.А. Мир моральных ценностей. М.: Знание, 1981. 64 с.

10. Титов В.А. Мораль познающая. М.: Знание, 1988. $64 \mathrm{c}$.

11. Братусь Б.С. Нравственное сознание личности (психологическое исследование). М.: Знание, 1985. 64 с.

12. Каган М.С. Философская теория ценности. СПб.: Петрополис, 1997. 205 с.

13. Мишаткина Т.В. Педагогическая этика. Ростовна-Дону: Феникс; Мн.: ТетроаСистемс, 2004. 304 с.

14. Жмуров С.А. Физическая культура как часть культуры // Образование в современном мире: проблемы и перспективы: сборник научных статей. Оренбург: ИПК ГОУ ОГУ, 2008. С. 130-146.

15. Васянович Г.П. Педагогічна етика: навч. посібник. Киев: Академвидав, 2011. 254 с.

16. Шадрина И.М. О структуре нравственной культуры учителя // Известия Самарского научного центра РАН. 2015. Т. 17, № 1 (2). С. 356-361.

17. Крылова Н.Б. Культурология образования. М.: Народное образование, 2000. 272 с.

18. Коровин С.С., Усманов В.Ф. Введение в теорию и дидактические основания физической культуры: курс лекций по теории и методике физической культуры. Оренбург: ОГПУ, 2007. 132 с.

19. Лубышева Л.И. Концепция физкультурного воспитания: методология развития и технология реализации // Физическая культура. 1996. № 2. С. 11-17.

20. Лубышева Л.И. Современный ценностный потенциал физической культуры и спорта и пути его освоения обществом и личностью // Теория и практика физической культуры. 1997. № 6. С. 10-15.

21. Запесоцкий А.С. Образование: философия, культурология, политика. М.: Наука, 2002. 456 с.

22. Андреев В.И. Педагогика: учебный курс для творческого саморазвития. Казань: Центр инновационных технологий, 2000. 608 с.

23. Кульневич С.В. Педагогика личности от концепций до технологий. Ростов-на-Дону: ТЦ «Учитель», 2001. 160 с.

24. Асмолов А.Г. Культурно-историческая психология и конструирование миров. М.: МПСИ; Воронеж: НПО «МОДЭК», 1996. 768 с.

25. Виленский М.Я. Ценности физической культуры и их интериоризация учащимися [Электронный pecypc] // Спорт в школе. 2007. Вып. № 17 (420). http://sportfiction.ru/articles/tsennosti-fizicheskoy-kulturyi-ikh-interiorizatsiya-uchashchimisya.

26. Жмуров С.А. Ориентированность студентов на ценности физической культуры: методические рекомендации для преподавателей и студентов вузов. Самара: СГПУ, 2009. 56 с.

27. Борисов А.Я. Формирование готовности студента - будущего учителя к приобщению учащихся к ценностям физической культуры: дис. ... канд. пед. наук: 13.00.01. Самара, 2010. 235 с.

28. Москаленко И.В. К проблеме изучения нравственных ценностей: нравственные национальные ценности // Сборники конференций НИЦ Социосфеpa. Прага: Vedecko vydavatelske centrum SociosferaCZ. 2011. № 16. C. 63-69.

29. Акимов И.Б. Содержание и методы приобщения учащихся к нравственным ценностям в процессе физического воспитания: автореф. дис. ... канд. пед. наук: 13.00.01. Самара, 2015. 26 с. 


\title{
THE UNITY OF PHYSICAL AND MORAL EDUCATION: VALUE FOUNDATIONS
}

(C) 2020

Klychkov Sergey Aleksandrovich, lecturer of Physical and Special Tactical Training Department Samara Law Institute of the Federal Penitentiary Service of Russia (Samara, Russian Federation)

\begin{abstract}
The paper substantiates the urgency of the problem of educating a person whose body and spirit are in harmonious unity - a healthy person both physically and morally. As one of the ways to solve this problem, the development of a moral personality within the framework of physical education is proposed. Evidence of the relationship of the physical and moral development of man in the process of education is given. The situation is substantiated that education is an introduction to values and it is proved that education of a person in harmony of body and spirit is possible in the process of his involvement in the values of physical culture and moral values. The specificity of value is revealed as a conscious meaning that defines a person's attitude to the world, to people and to himself and shows the place of relations in moral culture and in physical culture of a person. It is proved that values can be both components of physical culture, embodying ideals and ideas about the standard of a physically perfect person, and components of moral culture (a standard of moral man). The correlation of moral values and values of physical culture is determined and specific values are identified that are the value foundations of the unity of physical and moral education: «freedom», «justice», «dignity», «culture», «moral perfection», «mercy», «intellectuality». The essence of the moral component of physical education is revealed. It consists in the fact that in the process of such education personality's attitude to health, to a healthy lifestyle, to himself and to other people, as well as human morality are developed.

Keywords: education; physical education; moral education; value; value bases; unity; morality; culture; physical culture; moral culture; moral values; physical culture values; relationships.
\end{abstract}

$* * *$

УДК 372.854

DOI 10.24411/2309-4370-2020-11306

Статья поступила в редакцию 09.01.2020

\section{ОПЫТ ПРЕПОДАВАНИЯ ДИСЦИПЛИНЫ «НЕОРГАНИЧЕСКАЯ ХИМИЯ» В АГРАРНОМ ВУЗЕ}

(C) 2020

\author{
Кондрашова Анжела Владимировна, кандидат химических наук, \\ доцент кафедры микробиологии, биотехнологии и химии \\ Саратовский государственный аграрный университет имени Н.И. Вавилова \\ (2. Саратов, Российская Федераичя)
}

Аннотация. В данной статье рассматривается опыт преподавания дисциплины «Неорганическая химия» для студентов 1 курса на кафедре микробиологии, биотехнологии и химии в Саратовском государственном аграрном университете. Обосновывается идея, что содержание курса химии направлено на слияние теории и практики. Как показывает практика, данная дисциплина состоит из прочтения лекций с применением мультимедийного сопровождения, из выполнения лабораторных работ, практических занятий, тестовых контрольных. Предложен способ организации самостоятельной работы среди студентов, что приводит к успешному освоению образовательной программы высшего образования. Приведены примеры образцов заданий входного контроля для контроля остаточных знаний, образцов тестовых заданий и вопросов для правильной оценки знаний студентов. Автор показывает, что проведение таких видов контроля знаний студентов позволяет оценить уровень усвоения материала и выявить проблемные моменты. В статье дана оценка тому, что для осознанной и целенаправленной подготовки к практическим занятиям, лабораторной работе и экзамену используют разработанное на кафедре учебное пособие. Автор статьи пришел к выводу, что преподаватель выступает помощником для студентов на их пути самостоятельного решения небольших научных задач.

Ключевые слова: образование; учебный процесс; занятия; кафедра; неорганическая химия; входной контроль; лекция; лабораторная работа; университет; самостоятельная работа; тестирование; контрольная работа; учебное пособие; преподаватель; студенты; аграрный вуз; первый курс; мультимедийное сопровождение.

\section{Введение}

В современных условиях система образования требует использования в учебном процессе различных форм проведения занятий $[1 ; 2]$. На базе ФГБОУ ВО «Саратовский государственный аграрный университет» студенты многих направлений подготовки на первом курсе изучают дисциплину «Неорганическая химия». Обучение дисциплине ограничивается первым семестром.

На кафедре микробиологии, биотехнологии и химии данная дисциплина включает изучение основ- ных вопросов общей и неорганической химии и состоит из прочтения лекций, выполнения лабораторных работ, тестовых контрольных, самостоятельной работы студентов.

Цель. Содержание курса направлено на слияние теории и практики. Студентам в ходе изучения дисциплины предстоит изучить и осмыслить большой объем теоретического и практического материала.

Методы и результаты исследований

Студентам предлагается входной контроль [3-5], целью которого является: 